\title{
ACUsmart Continuous Renal Replacement Therapy Platform: Multicenter Pilot Study for Technical and Clinical Assessment (A.M.P. Study)
}

\author{
Mauro Neri ${ }^{\mathrm{a}} \quad$ Anna Lorenzin ${ }^{\mathrm{a}} \quad$ Massimo de Cal $^{\mathrm{a}} \quad$ Alessandra Brendolan ${ }^{\mathrm{a}}$ \\ Nicola Marchionna ${ }^{a}$ Sara Samoni $^{a}$ Monica Zanella $^{a}$ Silvia De Rosa ${ }^{b}$ \\ Francesca Martino $^{\text {a }}$ Zaccaria Riccic $^{c}$ Javier Maynar ${ }^{d}$ Georg Auzinger $^{e}$ \\ Gianluca Villa ${ }^{f}$ Didier Payen $^{\mathrm{g}}$ Michael Joannidis ${ }^{\mathrm{h}}$ Claudio Ronco $^{\mathrm{a}}$
}

a Department of Nephrology, Dialysis and Transplantation and International Renal Research Institute of Vicenza, San Bortolo Hospital, Vicenza, Italy; ${ }^{b}$ Department of Anesthesiology and Intensive Care, San Bortolo Hospital, Vicenza, Italy; ${ }^{\mathrm{C}}$ Department of Cardiology and Cardiac Surgery, Pediatric Cardiac Intensive Care Unit, Bambino Gesù

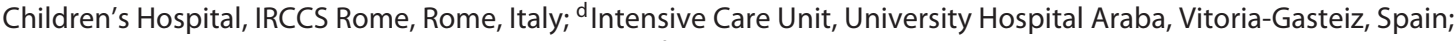
eKing's College Hospital, Denmark Hill, London, UK; f Department of Health Sciences, Section of Anaesthesiology, Intensive Care and Pain, University of Florence, Florence, Italy; 9 University Paris Diderot, Sorbonne Paris Cité, Paris,

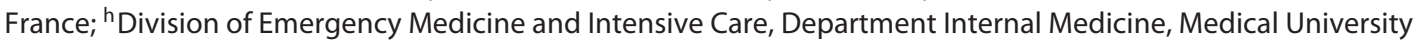
Innsbruck, Innsbruck, Austria

\section{Keywords}

Acute kidney injury · Continuous renal replacement therapy · Continuous veno-venous hemofiltration · Continuous veno-venous hemodialysis · Continuous veno-venous hemodiafiltration - Critical care .

Extracorporeal therapies - Continuous renal replacement therapy machines

\footnotetext{
Abstract

Background: ACUsmart (Medica S.P.A., Italy) is a new-generation, continuous renal replacement therapy (CRRT) machine for critically ill patients with acute kidney injury. We designed a multicenter international pilot study to provide a description of outlines of the ACUsmart system, evaluation aspects of functionality, usability, and feasibility, discriminating reasons of possible treatment's withdrawals or discontinuations and highlighting strong and weak points of the machine. Methods: Data of 23 CRRT (and 11 plasma ex-
}

change) treatments were collected from 4 intensive care units. Parameters such as treatment duration, downtime, delivered dose, and number and type of alarms were recorded. The general perception of the machine was quantified through the administration of a survey to each component of the evaluating staff. Results: A total treatment time of 447 h was carried with ACUsmart. Eleven continuous veno-venous hemofiltration, 4 continuous veno-venous hemodialysis, and 8 continuous veno-venous hemodiafiltration were performed. The average percentage of net treatment duration with respect to total treatment duration was $92.37 \%$. The mean prescribed dose and delivered dose were 26.33 and $24.10 \mathrm{~mL} / \mathrm{kg} / \mathrm{h}$, respectively. In general, the machine was rated by users involved as practical and easy to use, although few components need to be slightly improved. Conclusion: ACUsmart is a new multifunctional machine that meets most of the features required in a fourth-generation CRRT equipment.

(c) 2019 The Author(s)

Published by S. Karger AG, Basel

\section{KARGER}

E-Mail karger@karger.com www.karger.com/bpu (c) 2019 The Author(s) Published by S. Karger AG, Basel

Karger

Open access

This article is licensed under the Creative Commons AttributionNonCommercial-NoDerivatives 4.0 International License (CC BY NC-ND) (http://www.karger.com/Services/OpenAccessLicense). Usage and distribution for commercial purposes as well as any distribution of modified material requires written permission.
Mauro Neri

Department of Nephrology

Dialysis and Transplantation and International Renal Research Institute of Vicenza

San Bortolo Hospital, Viale Rodolfi 37, IT-36100 Vicenza (Italy)

E-Mail neri.mauro@gmail.com 


\section{Introduction}

Worldwide, continuous renal replacement therapy (CRRT) is the most used form of renal support for treating critically ill patients with acute kidney injury $[1,2]$. Since the birth of CRRT in 1970 [3], its delivery has been supplied by specifically dedicated machines [4]. Although the first generations (1970-1990) of these machines were basically derived from hemodialysis blood modules, in the last decades they have been designed exclusively as self-standing units for CRRT. Continuous arterio-venous hemofiltration presented important advantages in terms of control of circulating volume, hemodynamic stability, and possibility of nutritional support, but issues such as a difficult arterial cannulation and low solute clearances represented serious limitations in its application. In the late 1980s, the development of veno-venous CRRT systems (the second generation) represented a milestone and formed the basis for modern therapies. At that time, CRRT equipment borrowed some components from chronic hemodialysis machines such as blood and ancillary pumps to control volumes of dialysate and/or replacement fluid. The third-generation CRRT machines [5] allowed to reach greater blood- and auxiliary fluidsflow rate capabilities and safety features today recommended in every modern equipment. Finally, the fourth and latest generation of machines for CRRT has been developed [6-8]. The target points that manufacturers of these newest devices have tried to optimize are an accurate delivery of the prescribed dialysis dose by minimizing therapy downtime and a high safety for the patient (e.g., improvement of fluid balance precision [9]). Furthermore, easy utilization with a reliable performance of the therapy, optimization of alarms management, decreasing nursing workload, and improvement of user interface $[10,11]$ are further implementations to be reached.

As the fourth-generation CRRT devices is becoming reality, and in some occasion, it has become already $[6,8]$ the critical care and nephrology community needs to know how these machines may affect their workload and, especially, their patients.

ACUsmart (Medica S.P.A., Medolla, Modena, Italy; Fig. 1) is one of the fourth-generation CRRT devices: it is a multifunctional automatic machine for the delivery, performing, and control of continuous purifying treatment. The use of ACUsmart device provides to restore or replace the kidney functioning in patients affected by acute kidney injury (both isolated and concomitant with multiorgan failure syndrome), sepsis, or others diseases that can influence, temporarily or completely, the kidney function.

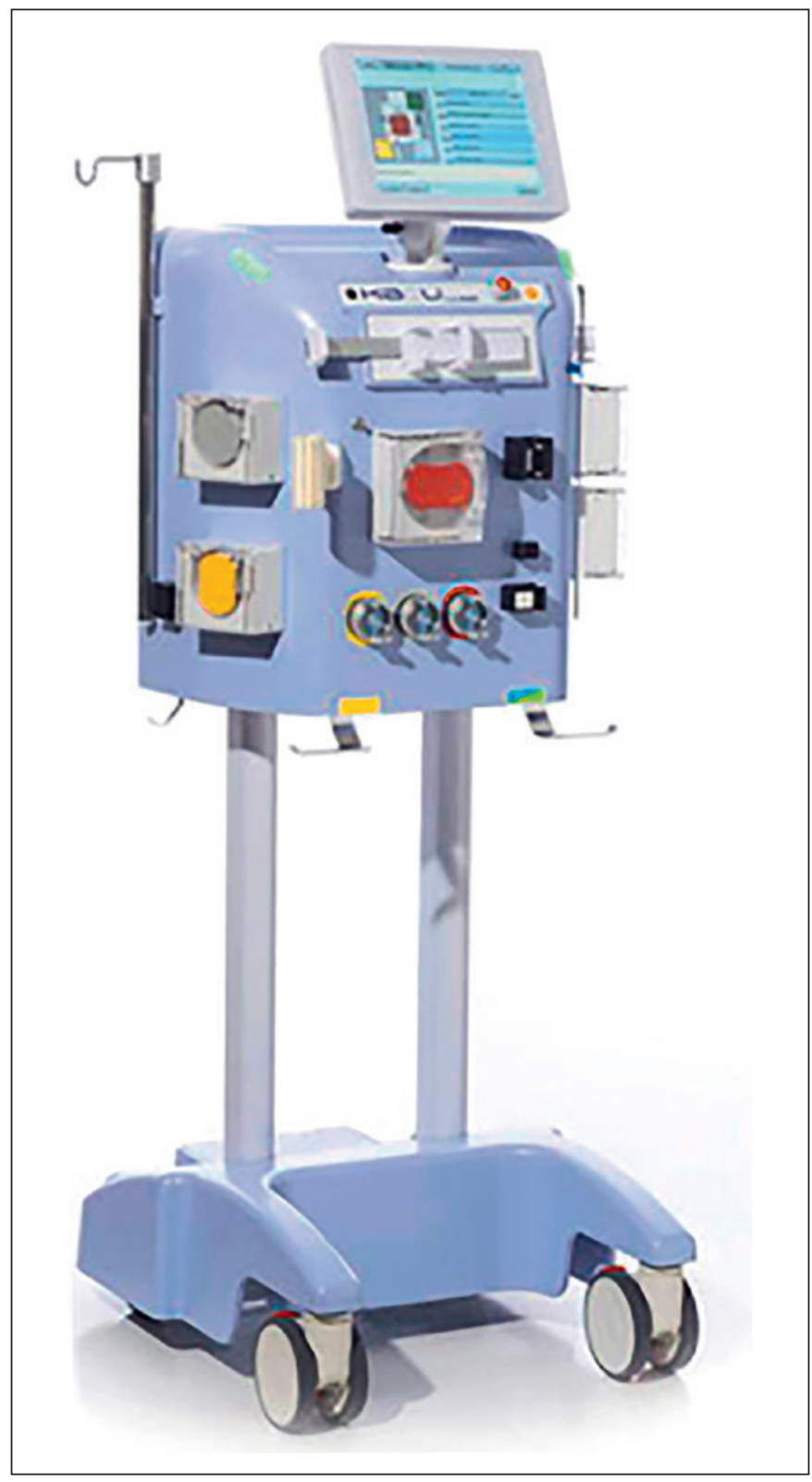

Fig. 1. Layout of Acusmart ${ }^{\circledR}$ machine.

A previous article [8] has already described the main technical peculiarities of ACUsmart. However, ACUsmart has not yet been tested in intensive care units (ICUs).

We designed a multicenter international pilot study to provide a description of outlines of the ACUsmart system, evaluation aspects of functionality, usability and feasibility, discriminating reasons of possible treatment's withdrawals or discontinuations, and highlighting strong and weak points of the machine. 


\section{Methods}

Study Design and Population

In this prospective multicenter international study, the ACUsmart system has been used in critically ill patients requiring extracorporeal blood purification therapy in the ICU. The local Ethics Committee approvals and signed informed consents were obtained in centers where they were necessary.

The study was carried out in 4 different ICUs: San Bortolo Hospital, Vicenza, Italy; Hospital Hua-Santiago, Vitoria-Gasteiz, Spain; Universitair Ziekenhuis, Brussels, Belgium; and Kings College Hospital, London, UK. Only patients who were expected to stay in the ICU for more than $24 \mathrm{~h}$ were considered for the enrollment. Patients less than 16 and those with pregnancy were excluded from this study. No variations on extracorporeal treatments indications and/or technical prescription derived from the inclusion in this protocol.

\section{Staff Training, Machine Usability, and Perception}

Users involved in the trial were physicians, nurses, engineers, and technicians belonging to ICUs and nephrology staff of each center. Nurses have been involved upon the decision of the head of the ICU or Nephrology departments of each center and have received a specific training. The training was considered successful when each user was able to perform and manage at least one in vitro simulating treatment. Company support was further available $24 \mathrm{~h} / 7$ days during the course of the study.

The general perception of the machine was quantified through the administration of a survey to each component of the evaluating staff. Aspects of functionality, usability, and feasibility during all the therapy phases of CRRT session were evaluated based on a score between 1 and 5 . The purpose was to highlight peculiarities, innovative features, and weaker points of ACUsmart.

\section{Data Collection}

Treatment data were recorded by ACUsmart device, and the data logs were downloaded and used for analysis. Treatment data consisted of treatment time, downtime, target prescribed and delivered doses, filter life span, and type and number of alarms.

\section{Statistical Analysis}

Descriptive data are expressed as mean \pm SD. Excel software (Microsoft, Redmond, WA, USA) was used for the analysis.

\section{CRRT and machine setting}

Fifteen patients requiring CRRT were recruited in the trial. In total, 23 CRRT filters (23 treatments) were used among the 4 ICUs. Based on study protocol, maximum 2 filters for each patient could be applied and enrolled in the study.

The selected modality and flows for each treatment were individualized and prescribed by physicians based on clinical needs of every single patient. In particular, 11 continuous veno-venous hemofiltration (CVVH), 4 continuous veno-venous hemodialysis (CVVHD), and 8 continuous veno-venous hemodiafiltration (CVVHDF) were performed. Regarding the anticoagulation therapy, regional citrate anticoagulation (available citrate solutions: trisodium citrate $[136 \mathrm{mmol} / \mathrm{L}]$ and ACDA disodium citrate [112.9 mmol/L]) was used in 6 treatments, heparin in 7 treatments and in 11 treatments no anticoagulant was used, based on specific clinical need of each single patient.
Twenty one treatments (for patients whose weight was higher than $50 \mathrm{~kg}$ ) were performed using the standard tubing set (priming volume $=60 \mathrm{~mL}$ ) and polysulfone filter Cureflo-180W (Asahi Kasei Kuraray Medical Co., Ltd., Tokyo, Japan), while 2 treatments (for patients whose weight ranged between 15 and $50 \mathrm{~kg}$ ) were performed using the pediatric tubing set (priming volume $=$ $50 \mathrm{~mL}$ ) and polysulfone filter Cureflo- 130W (Asahi Kasei Kuraray Medical Co., Ltd., Tokyo, Japan). Priming solution in all treatments was $0.9 \% \mathrm{NaCl}$ without any heparin dose.

CRRT therapies were applied with dialysate and replacement solutions from other manufacturers (B. Braun, Melsungen, Germany and Baxter, Deerfield, IL, USA).

\section{Plasma Exchange and Machine Setting}

Six patients were treated in plasma exchange (PE) modality, for a total of 11 plasmafilters (treatments). Dedicated tubing set and plasmafilter (Plasmaflo, Asahi Kasei Medical Co., Ltd., Tokyo, Japan) were used. The treatments were all performed in Kings College Hospital, London, UK.

\section{Results}

\section{General Evaluation and User Friendliness of ACUsmart System}

In general, ACUsmart is considered a small and compact CRRT machine. Based on scores assigned by the clinical staff involved, it allows for easy handling and movement (3.3/5). Visual and acoustic signals for alarms announcement are clear to perceive, especially in a noisy environment like ICU departments (3.9/5). The display is quite small (2.7/5), but its dimensions are adequate for an easy rotation on the vertical axis (3.5/5). The space of the frontal layout is perceived as well organized, especially during the preparation phase (3.6/5). Peristaltic pumps $(3.3 / 5)$, pressure sensors (3.5/5), and all other safety devices allocated in the machine (air bubbles detector, blood leak detector, safety automatic clamp, and so on) received good scores, both in terms of positioning and circuit handling. The installation phase of the disposable part of the tubing set on the heater of the machine was considered a bit cumbersome (1.9/5). The automatic adjustment of the blood level in the air removal chamber in the return line, achieved by 2 ultrasound probes, was considered very useful. However, the shape of the disposable chamber and hemodynamics inside it may lead to some stagnation of blood and increase risks of clotting. Dialysate/replacement and effluent scales received a good mark (3.0/5), especially from nurses, because the maximum weight potentially to load (15 kg) was considered practical, potentially reducing the frequency of bags change procedures.

The pediatric tubing set can be used for patients whose weight is higher than $15 \mathrm{~kg}$. Blood flow was accurate for
Neri et al. 


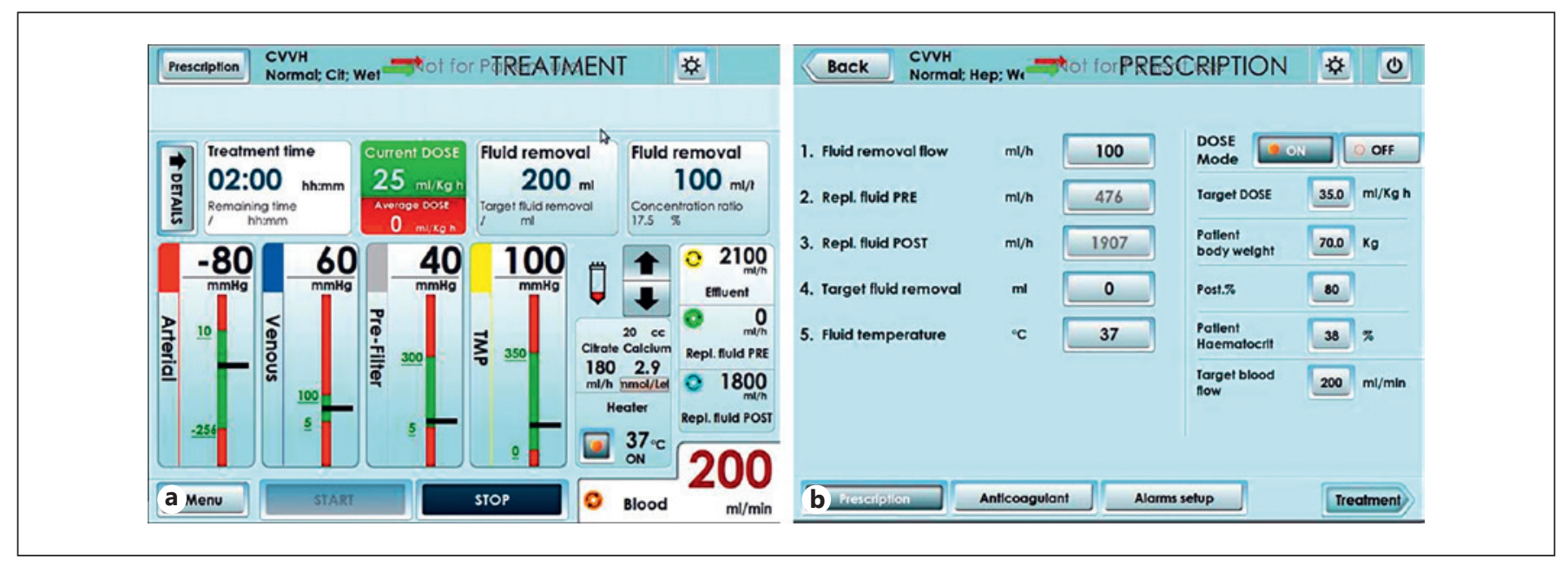

Fig. 2. a Screenshot of the treatment page. b Screenshot of the prescription page in "dose prescription mode." $\mathrm{CVVH}$, continuous veno-venous hemofiltration.

Table 1. Main flow parameters adopted during CRRT treatments with ACUsmart

\begin{tabular}{lllll}
\hline CRRT modality & Blood flow, mL/min & Replacement flow, $\mathrm{mL} / \mathrm{h}$ & Dialysate flow, mL/h & NET ultrafiltration flow, mL/h \\
\hline CVVH & $212 \pm 26$ & PRE $=2,250 \pm 463$ & - & $117 \pm 60$ \\
CVVHD & $143 \pm 15$ & POST $=1,375 \pm 518$ & $1,000 \pm 0$ & $100 \pm 1$ \\
CVVHDF & $166 \pm 35$ & - & $1,508 \pm 1826$ & $100 \pm 46$ \\
\hline
\end{tabular}

CRRT, continuous renal replacement therapy; CVVH, continuous veno-venous hemofiltration; CVVHD, continuous veno-venous hemodialysis; CVVHDF, continuous veno-venous hemodiafiltration.

values of $50 \mathrm{~mL} / \mathrm{min}$ (increments of blood flow rate is 1 from 1 to $30 \mathrm{~mL} / \mathrm{min}, 5$ from 30 to $400 \mathrm{~mL} / \mathrm{min}$ ). However, blood and effluent pumps work in a discontinuous way for very low flows (1-30 $\mathrm{mL} / \mathrm{min})$.

Also, software and graphic user interface was evaluated and considered immediate, comprehensive (3.2/5), and with a good setup and organization on the screen (3.4/5). Figure $2 \mathrm{a}$ shows a screenshot of the display during the treatment. A new function of the machine during the prescription phase, the "dose mode" (Fig. 2b), deserves a special mention. By setting the desired prescribed dose and other parameters, such as weight and hematocrit of the patient, the machine automatically calculates replacement (pre- or postinfusion) and/or dialysate flows. Furthermore, the cumulative dose value (Fig. 2a) that takes into account the downtime accumulated during the treatment, is continuously displayed and updated: this value can be compared with the prescribed dose and eventually lead to an adjustment of the clinical prescription, following the new concept of "dynamic prescription" proposed by ADQI group in 2016 [12-15].

\section{CRRT Setting and Running Time}

All patients treated in CRRT with ACUsmart machine had central venous catheter ( $43 \%$ in femoral and $57 \%$ in jugular position).

Table 1 summarizes the average flows adopted in different CRRT modalities.

Total machine running time in CRRT was $447 \mathrm{~h}$. In particular, $144 \mathrm{~h}$ in CVVH, $78 \mathrm{~h}$ in CVVHD, $207 \mathrm{~h}$ in CVVHDF, and $18 \mathrm{~h}$ in $\mathrm{CVVH}$ with pediatric tubing set. Mean total treatment durations were 16:01 $( \pm 06: 37)$ in CVVH, 19:32 ( \pm 07:59) in CVVHD, 25:49 ( $\pm 19: 37)$ in CVVHDF, and 09:07 $( \pm 02: 03)$ in CVVH with pediatric tubing set. Table 2 , instead, describes the average and maximum treatment duration in function of the anticoagulation therapy. 
Table 2. Influence of anticoagulation modality on duration of CRRT treatments using ACUsmart

\begin{tabular}{lcll}
\hline & $\begin{array}{l}\text { Number } \\
\text { of treatments }\end{array}$ & $\begin{array}{l}\text { Average } \\
\text { treatment } \\
\text { duration, } \\
\text { hh:mm }\end{array}$ & $\begin{array}{l}\text { Maximum } \\
\text { treatment } \\
\text { duration, } \\
\text { hh:mm }\end{array}$ \\
\hline $\begin{array}{l}\text { No anticoagulation } \\
\text { Heparin }\end{array}$ & 10 & $16: 03$ & $22: 36$ \\
Citrate & 7 & $16: 36$ & $24: 12$ \\
Total & 6 & $29: 12$ & $73: 06$ \\
\hline
\end{tabular}

CRRT, continuous renal replacement therapy.

Table 3. Overview of reasons for therapy interruption

\begin{tabular}{lr}
\hline Total number of CRRT treatments & 23 \\
Disconnections for clinical reasons & 8 \\
Disconnection for technical reasons & 13 \\
Disconnections for ending therapy & 2 \\
\hline
\end{tabular}

CRRT, continuous renal replacement therapy.

Table 4. Discrimination and number of events of technical reasons for therapy interruption

Technical reasons of interruption $\begin{aligned} & \text { Number of } \\ & \text { events }\end{aligned}$

Coagulation of the filter 4

Air in the return line 3

Machine alarm: "Critical fluid balance error" 2

Machine alarm: "Level pump driver fault" 2

Clot in the venous chamber 1

Machine alarm: "Effluent pressure too high" 1

The average percentage of net treatment duration with respect to total treatment duration has been $92.37 \%$ that can be considered an optimal value. The mean prescribed dose and delivered dose, which considers only downtime and no other biological reasons (such as protein layer and coagulation phenomena), were 26.33 and $24.10 \mathrm{~mL} / \mathrm{kg} / \mathrm{h}$, respectively. Based on the prescription method based on dose setting (Fig. 2b) and having the possibility to continuously monitor the current dose displayed on the monitor, the mean downtime and the mean ratio delivered/prescribed doses can be considered very low.

\section{Reasons for CRRT Therapy Interruption}

In Tables 3 and 4 , the reasons of therapy interruptions are reported. They are divided in 3 main categories: clinical (e.g., death, metabolic alkalosis), technical, and end of therapy.

During the study, a focus has been carried out on technical reasons of disconnection. In particular, in Table 4 , technical reasons and number of events are reported.

Events causing filter coagulation are entirely related to use of no anticoagulant. Furthermore, disconnections due to air infusion and "critical fluid balance error" are related to an incomplete rupture of neck of replacement bags and can be considered as user errors.

\section{PE Setting and Running Time}

All patients treated in PE with ACUsmart machine had central venous catheter $(64 \%$ in femoral and $36 \%$ in jugular position). Total machine running time in PE was $38 \mathrm{~h}$. Mean treatment duration was 03:28 \pm $00: 51$.

\section{Discussion}

Several fourth-generation CRRT machines have appeared on the market over last 2 years. Although further developments and improvements are planned for the years to come and some of new technologies have not reached their full clinical potential; yet, these new devices are already modifying the scenario of applied technology to critically ill patients. In addition to safety features of the therapy, other aspects have become important in further developments including smooth treatment performance, easy usability, and consequent efficient use of resources, application of a standardized nomenclature [16-18], and possibly, a biofeedback-controlled treatment using signals from patients and machines to drive treatment parameters. In literature, there is already some idea of how these devices will evolve from today to the next 10 years [19].

This multicenter beta trial describes the first use and evaluation of one of these new machines, ACUsmart. Performance, safety, and efficiency of the device in several CRRT sessions and modalities have been assessed.

This trial demonstrated that ACUsmart is able to satisfactorily perform CRRT in all modalities and PE, adopting as anticoagulation therapy both heparin and
Neri et al. 
citrate solutions. Confirming the results already published by our group [8], the device was able to maintain good fluid balance in all patients treated with CRRT. Mean downtime (7.63\% of total time of treatment) can be considered very satisfactory to get the difference between prescribed and delivered dose as low as possible. In comparison with other studies and fourth-generation machines, results were similar $[6,7]$. These results can be related to the "dose prescription mode" settable during prescription phase with ACUsmart.

During the trial, no safety concern was raised. However, based on comments from users in all centers involved, some suggestions for a further improvement of the machine were identified. In particular, the air removal chamber placed in the return line seems to be the most critical point of the extracorporeal circuit in terms of inducing clotting. Although only one treatment was stopped for this reason, it was frequent to visually find some clots inside the chamber during the therapy. The cylindrical shape of the PVC-plastic chamber does not guarantee adequate fluid dynamics, determining some blood stagnation and low shear rate in the inner wall of the chamber. A revised and renovated design of the chamber has been strongly suggested. Furthermore, feedback of complete trend of net ultrafiltration volume along treatment duration should be provided and developed as software component of the machine.

\section{Conclusion}

ACUsmart CRRT machine has been validated as a fourth-generation-renal replacement therapy device. The platform can perform different treatments and operate in various modalities. CRRT has been provided in a safe and efficient way using different modalities and anticoagulation therapies. The reliability and accuracy of the device is confirmed by a strict concordance between delivery and prescription of various techniques of renal replacement therapy. Innovative characteristics, such as the "dose prescription mode," make this platform particularly adherent to the current nomenclature (14-15) and suitable for dynamic prescription and delivery based on the principles of precision CRRT as suggested by the ADQI consensus group (12).

\section{Acknowledgments}

The authors would like to thank the clinical and nursing staff of all the centers and departments involved in the study for their assistance and experience.

\section{Disclosure Statement}

The study was sponsored by Medica. However, Medica had no influence on the study design, results interpretation, manuscript preparation, and decision of submission.

\section{References}

1 Bellomo R, Ronco C: Blood purification in the intensive care unit: evolving concepts. World J Surg 2001;25:677-683.

2 Chawla LS, Bellomo R, Bihorac A, Goldstein SL, Siew ED, Bagshaw SM, Bittleman D, Cruz D, Endre Z, Fitzgerald RL, Forni L, Kane-Gill SL, Hoste E, Koyner J, Liu KD, Macedo E, Mehta R, Murray P, Nadim M, Ostermann M, Palevsky PM, Pannu N, Rosner M, Wald R, Zarbock A, Ronco C, Kellum JA: Acute kidney disease and renal recovery: consensus report of the acute disease quality initiative (ADQI) 16 workgroup. Nat Rev Nephrol 2017;13:241257.

3 Kramer P, Wigger W, Rieger J, Matthaei D, Scheler F: [Arteriovenous haemofiltration: a new and simple method for treatment of overhydrated patients resistant to diuretics]. Klin Wochenschr 1977;55:1121-1122.

4 Ronco C: Evolution of technology for continuous renal replacement therapy: forty years of improvements. Contrib Nephrol 2017;189: 114-123.
5 Cruz D, Bobek I, Lentini P, Soni S, Chionh $\mathrm{CY}$, Ronco C: Machines for continuous renal replacement therapy. Semin Dial 2009;22: 123-132.

6 Schläpfer P, Durovray JD, Plouhinec V, Chiappa C, Bellomo R, Schneider A: A first evaluation of OMNI ${ }^{\circledR}$, a new device for continuous renal replacement therapy. Blood Purif 2017; 43:11-17.

7 Broman M, Bell M, Joannes-Boyau O, Ronco C: The novel prismax continuous renal replacement therapy system in a multinational, multicentre pilot setting. Blood Purif 2018;46: 220-227.

8 Neri M, Lorenzin A, Brendolan A, Garzotto F, Ferrari F, De Rosa S, Bonato R, Villa G, Bazzano S, D"Ippoliti F, Ricci Z, La Manna G, Ronco C: Development of the new kibou ${ }^{\circledR}$ equipment for continuous renal replacement therapy from scratch to the final configuration. Contrib Nephrol 2017;190:58-70.

9 Ronco C, Ricci Z, Bellomo R, Baldwin I, Kellum J: Management of fluid balance in crrt: a technical approach. Int J Artif Organs 2005; 28:765-776.

10 Houlle-Veyssiere M, Courtin A, Zeroual $\mathrm{N}$, Gaudard P, Colson PH: Continuous venovenous renal replacement therapy in critically ill patients: a work load analysis. Intensive Crit Care Nurs 2016;36: 35-41.

11 Fealy N, Aitken L, Toit Ed, Baldwin I: Continuous renal replacement therapy: current practice in australian and New Zealand intensive care units. Crit Care Resusc 2015;17:8391.

12 Ostermann M, Joannidis M, Pani A, Floris M, De Rosa S, Kellum JA, Ronco C: Patient selection and timing of continuous renal replacement therapy. Blood Purif 2016;42:224237.

13 Bagshaw SM, Chakravarthi MR, Ricci Z, Tolwani A, Neri M, De Rosa S, Kellum JA, Ronco C: Precision continuous renal replacement therapy and solute control. Blood Purif 2016; 42:238-247. 
14 Cerdá J, Baldwin I, Honore PM, Villa G, Kellum JA, Ronco C; ADQI Consensus Group: Role of technology for the management of AKI in critically ill patients: from adoptive technology to precision continuous renal replacement therapy. Blood Purif 2016;42:248265.

15 Murugan R, Hoste E, Mehta RL, Samoni S, Ding X, Rosner MH, Kellum JA, Ronco C: Precision fluid management in continuous renal replacement therapy. Blood Purif 2016; 42:266-278.
16 Neri M, Villa G, Garzotto F, Bagshaw S, Bellomo R, Cerda J, Ferrari F, Guggia S, Joannidis M, Kellum J, Kim JC, Mehta RL, Ricci Z, Trevisani A, Marafon S, Clark WR, Vincent JL, Ronco C: Nomenclature for renal replacement therapy in acute kidney injury: basic principles. Crit Care 2016; 20:318.

17 Villa G, Neri M, Bellomo R, Cerda J, De Gaudio AR, De Rosa S, Garzotto F, Honore PM, Kellum J, Lorenzin A, Payen D, Ricci Z, Samoni S, Vincent JL, Wendon J,
Zaccaria M, Ronco C: Nomenclature for renal replacement therapy and blood purification techniques in critically ill patients: practical applications. Crit Care 2016;20: 283.

18 Bellomo R, Ronco C, Mehta RL: Nomenclature for continuous renal replacement therapies. Am J Kidney Dis 1996;28:S2-S7.

19 Clark WR, Neri M, Garzotto F, Ricci Z, Goldstein SL, Ding X, Xu J, Ronco C: The future of critical care: renal support in 2027. Crit Care 2017;21:92. 